\title{
Integrated Platform from CAD to CNC: A Survey
}

\author{
Christophe Danjou, Julien Le Duigou, and Benoît Eynard \\ Mechanical Engineering Systems Department, Université de Technologie de Compiègne, \\ Mechanical laboratory Roberval UMR UTC/CNRS 7337, \\ CS 60319, 60203 Compiègne cedex, France \\ \{christophe.danjou, julien.le-duigou, benoit.eynard\}@utc.fr
}

\begin{abstract}
Nowadays, interoperability is essential to ensure the Product Lifecycle Management (PLM). However there are still some barriers to interoperability both technical and scientific which inhibit exchanges between the different information systems. This exchange can occur at different levels. In this paper the first one deals with exchanging and sharing information during the industrialization stage on the chain CAD-CAM-CNC. The second level developed concerns the chain of information systems materialized by the link between PDM-MPM-ERP. This paper identifies first the locks to interoperability and then explores the work done on those links with an interoperability point of view in order to remove the barriers identified.
\end{abstract}

Keywords: Interoperability, Integrated Design and Manufacturing, CADCAM-CNC.

\section{Introduction}

Face to the globalization and the growing competition concerning product costs, companies must constantly increase their productivity. In a "Rapid-development" context, companies have to improve their industrialization ability. In fact, they must industrialize their products and processes with an increasing speed, lower costs and maintaining a high level of quality.

French FUI project called ANGEL (Atelier Numérique coGnitif intEropérable et agiLe) will focus on the capitalization of cuts know-how in order to improve the competitiveness of enterprises in developing tools and methods to retrieve information from the numerical-control machine-tool. To achieve the information flow bi-directionality (capitalization and control of machines), the systems must be able to exchange information and to use these information.

Defining interoperability as the exchange of information between systems and the use of their functionality, interoperability can be a solution to treat the continuity of digital flow. It also ensures capitalization of technical know-how linking the different stages from the design to manufacturing.

The next section deals with interoperability state of the art and existing solutions to enhance it. Third section analyses papers which deals about the information exchange 
and share in order to show the link between the different industrialization stages. The fourth section concludes this paper and gives our research framework concerning the integrated platforms interoperability.

\section{State of the Art}

\subsection{Interoperability Definition}

According to Kosanke [1] a careful chosen web search produces 22 definitions of interoperability. Following the interpretation and the people who use it, the term interoperability can make different senses. This explains why a large number of definitions can be found in the literature. IEEE [2] defines interoperability as "the ability of two or more systems or components to exchange information and to use the information that has been exchanged". ATHENA [3] and INTEROP NoE [4] projects define interoperability for enterprises. In this case, interoperability is the ability of interaction between companies or at least between parts of them. Vernadat [5] defines interoperability as the "ability to communicate with peer systems and access their functionality". This definition highlights the need to exchange functionalities. But here we will use Wegner's [6] definition which describe interoperability as "The ability of two systems (or more) to communicate, cooperate and exchange services and data, thus despite the differences in languages, implementations, executive environments and abstraction models". ANGEL project will focus on the industrialization phase interoperability between the different CAX systems and Information Systems.

\subsection{Interoperability Levels}

According to EIF [7] there exist three levels of interoperability: Technical level, Semantic level and Organizational level. A system is interoperable if and only if it satisfies the three levels of interoperability at every moment. The technical level ensures the continuity of the information flow through tools and technological solutions. The semantic one ensures the information sharing and services to keep the semantics flow. The organizational level deals with the processes, users and those involved in the operation of the system [8]. Most articles in the literature tend to satisfy the technical and semantic levels. However organizational level barriers are less treated in the literature because of they are associated human kind problems.

\subsubsection{Technical Level}

To implement interoperability between two systems, two solutions are possible: the integration point by point or the "Enterprise Application Interface" interoperability oriented [9].

In the point-to-point strategy, the number of translators is $\left(n^{2}-n\right) / 2$ for the direct translation. It seems obvious that such architecture is not feasible given the number of translators to develop but also for all maintenance costs necessary to ensure the proper 
functioning of the system [10]. In contrast to the point-to-point strategy the mediator strategy has been developed and appears to be promising [11]. With this architecture there is a greater agility of information systems and a lower cost of interface. With an architecture based on a mediator, the number of relations is equal to the number of systems in architecture, considering mediator as a bidirectional translator.

According to Booth [12], service oriented architecture (SOA) is another way to ensure interoperability. Web services provide a means to interoperate between applications regardless of platform or environment in which they are executed. Combining SOA and mediator, we obtain the model developed by Paviot [8]. This model is shown in Figure 1 with a service-oriented information mediator. Such a mediator must fulfill three basic functions defined by Bénaben [13]: Data conversion and provision, Application Management and Collaborative processes orchestration. However, this system based on the mediator may have some disadvantages developed by Zimmerman [14]. In fact, he points that a mediator failure will cause the entire system failure. In addition, if the semantic flow is too large, the mediator may be a bottleneck and may limit the semantic flow. The SOA and the mediator appear as a serious solution to interoperability for the industrialization phase. There are also mediators of mediators which can help systems to translate its own information before sending it to the all system.

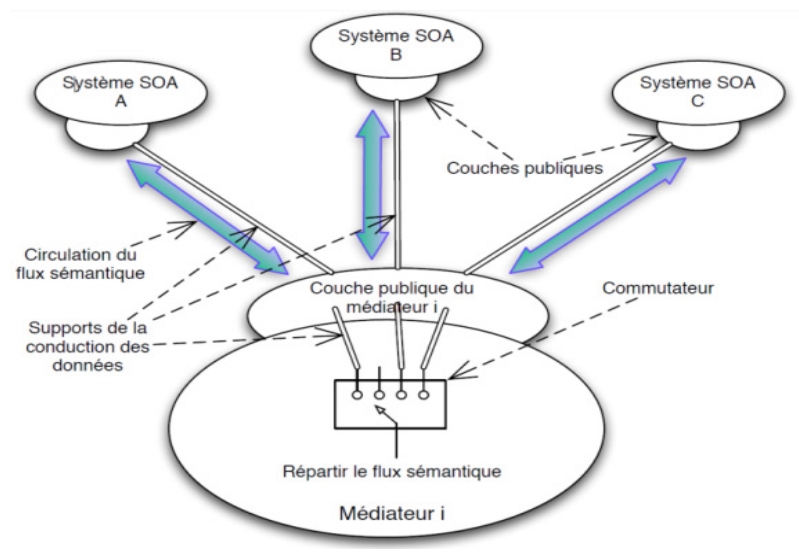

Fig. 1. Mediator distribution function of multiscale mediation [12]

\subsubsection{Semantic Level}

According to the standard ISO 14258 there are three different approaches to achieve semantic interoperability: Integration, Unification and Federation.

The integration is based on the existence of a common format for all models. Unification is based on a high level common format. Finally, the federation is based on the use of ontologies and Semantic Web standards in order to have automated transfers and routing of information between heterogeneous applications.

Many works use unifying approach [8], [15] which gets more flexible and more dynamics aspects than integration approach as seen before. It is necessary to translate 
data from one system to another so that there is the possibility of information exchange. To achieve interoperability through unifying approach, it is possible to use standards such as STEP standard [16]. The STEP standard is an open and normalized standard that aims to promote the data exchange in a format which is understandable and shared by all. According to [17], the STEP standard provides a neutral, a sustainable and a scalable data exchange format. In the last years, STEP-NC, a new standard format with enriched data has been developed in order to improve the systems interoperability [18] by integrating processing data. Moreover, according to the NIST [19] the standard can potentially save up to a billion dollars a year by reducing the costs of interoperability in sectors such as automotive, aerospace and shipbuilding. The STEP standard has positioned itself as a viable alternative to product-oriented interoperability. The concept of product-oriented interoperability was introduced by Baïna and describes the ability for a company to manage, share and exchange product information for more transparency for the user [9]. In the same way the PPO Model uses a SOA architecture for placing the model at the center of expertise that revolve around. This expertise can be related to the product (consultancies and methods expert for example) but may also be related to organizational, policy aspects, etc... However, unification imposes to totally appropriate information models of each system due to the meta-data use.

The federation is based on ontologies or web-services. "An ontology is a vocabulary of such terms (names of relations, functions, individuals), defined in a form that is both human and machine readable" [20]. More broadly an ontology is the structured set of terms and concepts representing the meaning of an information field, whether as a metadata namespace or the elements of a knowledge field. Besides ontologies the federation is also based on the semantic web standards which provide additional necessary information to understand. So that simplifies the programming and maintenance of knowledge based on web services architecture [21], [22]. According to Mellor [23] and the OMG that develops Model-Driven Engineering (MDE), ontologies are also solutions for the implementation of Model-Driven architecture (MDA) which is based on four ontological levels [24]. Hence the MDA provides a basis to enhance formalization of trade and obtain solutions to achieve interoperability through a unifying approach. To develop the interoperability between the different stages of the industrialization, it is necessary to use the same language for all the systems. This is why unification can be an approach for semantic interoperability. Moreover, federative approach can be used for interoperability between information systems and each industrialization stages. Finally, the interoperability between information systems can be seen as integration because they must exchange data and functionalities. As Kosanke says [1], interoperability cannot exist in a single approach, but certainly as an aggregation of three approaches in order to conserve the semantic flow.

\subsubsection{Organizational Level}

According to Vernadat [25], the organizational aspects of interoperability define the objectives, ensure coherence and process coordination. It is the ability to make collaboration between different structures and organizations if they wish to exchange information, although they may have different structures and different internal processes. In addition, process must be managed by placing users at the heart of the 
problem [26]. It is necessary to focus on functional aspect of the system to be as accessible as possible. Work on the human-machine interface systems is necessary for organizational interoperability. To achieve interoperability at the organizational level certain barriers must be removed [27]: Definition of responsibility (who is responsible for what?), Definition of authority (who is authorized to do what?) and Incompatibility of organization structures (matrix vs. hierarchical ones). In fact, once these three barriers are treated, it is possible to define the information exchange process and the information use.

In this part, it appears that interoperability deals with different level in order to ensure the data exchange, the data use and the functionalities use of other systems. The interoperability of the industrialization phase must be established through the three different interoperability levels in order to match the integration continuum.

\section{Interoperability for Industrialization}

This section exposes the study of the link between the different industrialization phases. We look at these links in "interoperability" terms to determine the interoperability levels and the methods used. The integrated design/industrialization platforms contain various expert software (CAD, Simulation, CAM ...) and different systems to support these expertises (PDM (Product Data Management), MPM (Manufacturing Process Management), ERP (Enterprise Resource Planning Information), MES (Manufacturing Execution System)). In the chain of industrialization three types of links are identified:

- The Design / Simulation link covering links between CAD software, Simulation and PDM

- The Design / Manufacturing link covering links between CAD, CAM, PDM, MPM, ERP and MES

- The Design / Assembly link covering the same software links and information systems as above, but taking into account a different expertise (assembly and nonmanufacturing)

\subsection{Design / Simulation Link}

The design / simulation can help designers to make technology choices for their designs through the information from the simulation. In fact with the bidirectionality of the design / simulation chain, validation of the design may result from a smaller number of exchanges between the design and simulation as a result of increased knowledge capitalization. Reducing the number of round trips between the numerical model and simulation design, development time are reduced consequently the development cost are reduced too. Nguyen Van [28] defines architecture with collaborations loops between design and simulation. Via this architecture he ensures the preservation of the semantic link using STEP standard. To save this link Assouroko [29] connect every ontologies thanks to the RelationShip Manager principle (RsM). Li [30] defines ontologies in order to enrich the data and information exchange with Annotation. According to Barbau [31], OntoSTEP provides an OWL representation for EXPRESS data, which allows the 
creation of semantically enriched product models. Catalano [32] also uses Ontologies to develop a new model called Product Design Ontology which allow to index information on the CAD model. Troussier [33] uses the dependencies that exist between the information contained in the notes of calculation" to ensure interoperability. In the same way, Etienne [34] develop a PPO Kernel in order to create interoperability between the CAD expert tool. Valilai [35] have develop the INFELT STEP platform which make possible the interoperability between CAD and Simulation systems. Similarly, Nassehi [36] has developed a "universal CNC manufacturing platform" with interfaces which allow to connect CADs and simulation systems. According to Jun [37] closed-loop PLM focuses on tracking and managing the information on the whole product lifecycle, with information feedback. Pratt [38] and Newman [39] define the exchanges CAD-Simulation allowed through STEP and STEP-NC standard. Biahmou [40] develops a translator called CAMAT (CATIA-MATLAB Translator) insuring the interoperability between Design and Simulation. According to Tan [41] Product Service System which places the simulation for design is a new organizational interoperability.

\subsection{Design / Manufacturing Link}

The capitalization of knowledge from the machine tool enables an optimized design for manufacturing. Moreover, if a problem is corrected directly on the CNC interoperability between design and manufacturing can propagate upstream changes. Harik [42] develop a tool for the Usiquick project which enriches the CAD model in order to define the machining program and tool path. Valilai [35] with the INFELT platform allows the interoperability between CAD and CAM systems. Delplace [43] developed an automated cell to promote the casting process full integration. Newman [39] defines the CAD-CAM exchanges through STEP-NC standard. Nassehi [36] has developed interfaces to connect CAD and CAM systems on the "universal platform". Martin [44] developed a tool based on the Visual Basic language to create a "mediator" for all the APIs to ensure the link between design and foundry manufacturing. Similarly Paviot [8], uses mediator to link ontologies. At the same time, he develops a model based on "semantic tags", which deals with the interoperability semantic level. Le Duigou [45] deals with interoperability between design and manufacturing defining a generic data model. He first uses a unifying approach then he uses the integration to complete his data model thus ensuring the semantic flow. According to Kuo [46], based on artificial intelligence, the intelligent DFX systems help the designer to make choices thanks an experience data basis. As seen before, closed-loop PLM [37] ensures technical interoperability between design and Manufacturing. Through the UbiDM (design and manufacturing via ubiquitous computing technology), Suh [47] allow the transfer of data from the different Lifecycle stages. Tan [41] deals with the organizational interoperability between design and Manufacturing.

\subsection{Design / Assembly Link}

The link between design and assembly essentially helps the designer in the technical choices process. Demoly [48] defines a Multi-Views Oriented assembly model (MUVOA) which aims to ensure the link between design and assembly. It also treats the organizations problems. Mantripragada [49] develops a tool called Assembly Oriented Design (AOD) which decomposes each assembly into sub-assembly 
informing designers the way to realize a system. The NIST [50] has developed the Core Product Model which treats the link between Design and Assembly. Jun [37] ensures technical interoperability for the link design/Assembly.

\subsection{Synthesis}

In order to analyze this literature review, the three levels of interoperability seen previously are used: Semantical level, Technical level and Organizational level. From these elements, the literature review can be summarized in a double-entry table to classify the different jobs in the category that corresponds to it. The results of this analysis are presented in Table 1.

Table 1: Synthesis of the literature survey

\begin{tabular}{|c|c|c|c|}
\hline & $\begin{array}{l}\text { Technical } \\
\text { Level }\end{array}$ & $\begin{array}{l}\text { Semantic } \\
\text { Level }\end{array}$ & $\begin{array}{l}\text { Organizational } \\
\text { Level }\end{array}$ \\
\hline Design / Simulation link & $\begin{array}{c}\text { [33]; [35]; [36]; } \\
\text { [37]; [40] }\end{array}$ & $\begin{array}{c}{[28] ;[29] ;[30] ;} \\
{[31] ;[32] ;[38] ;} \\
{[39]}\end{array}$ & [41] \\
\hline Design / Manufacturing link & $\begin{array}{l}\text { [8]; [35]; [36]; } \\
\text { [37]; [42]; [43]; } \\
\text { [44]; [46]; [47] }\end{array}$ & [8]; [39]; [45] & [41] \\
\hline Design / Assembly link & [37]; [46]; [49] & {$[45] ;[48] ;[50]$} & [41]; [48] \\
\hline
\end{tabular}

Literature extensively addresses the barriers related to technical and semantic levels. However barriers related to organizational level as associated human nature problems are less treated in the literature [51]. On the technical level, SOA systems and mediators are mainly used. On the semantic level, federative approach and ontologies are the most exploited.

\section{Conclusion and Future Work}

As explained in $\mathrm{Xu}$ work [52], STEP-NC can wear through its rich data format, much information that can be integrated in the digital flow CAD-CAM-CN. In opposition to the multi-interfaces needs [53] this standard let compile all the information from the design, simulation and manufacturing. STEP-NC format provides bidirectional digital flow because it allows feedback from the manufacturing and simulation stages to the design.

Given the state of the work already completed for interoperability between design and simulation phases [54], it appears that interoperability between PDM / MPM / ERP / MES has been little addressed. Indeed, MPM appears as an essential element for lifecycle management of production lines. According to [55], the MPM is the only software able to provide a link between the early phases such as CAD and PDM, and downstream applications, such as ERP and MES.

This paper presents the state of the art of the various interoperability levels. Three interoperability levels (semantic, technical and organizational) exist and we have seen the 
different approaches to overcome interoperability barriers. We will use OntoSTEP-NC an ontology based on STEP-NC format for CAD-CAM-CNC chain - as a basis to support ontology for MPM model. OntoSTEP-NC seems a possible way to improve the design / industrialization chain interoperability. This axis will be studied in our future work.

Acknowledgments. This work is done in the French FUI project ANGEL. We also thank all consortium partners for their contribution during the development of ideas and concepts proposed in this paper.

\section{References}

[1] Kosanke, K.: ISO Standards for Interoperability: a comparison. In: Proceedings of the 1st International Conference on Interoperability of Enterprise Software and Applications, pp. 55-64 (2005)

[2] IEEE, IEEE (Institute of Electrical and Electronics Engineers): Standard Computer Dictionary-A Compilation of IEEE Standard Computer Glossaries (1990)

[3] ATHENA, Document Deliverable D.A1.1.1, Project A1: Enterprise Modelling in the Context of Collaborative Enterprises ATHENA, EU IP- Project - No 507849 (2004)

[4] INTEROP, Knowledge map of research in interoperability in the INTEROP NoE, Deliverable D1.1, EU-NoE Project IST-508 011 (2004), http://www.interop. noe.org

[5] Vernadat, F.: Enterprise Modelling and Integration: principles and applications. Chapman \& Hall (1996) ISBN 0412605503

[6] Wegner, P.: Interoperability. ACM Computing Surveys (CSUR) 28(1), 285-287 (1996)

[7] EIF: European Interoperability Framework. White Pages, pp. 1-40 (2004)

[8] Paviot, T.: Méthodologie de résolution des problèmes d'interopérabilité dans le domaine du Product Lifecycle Management. Thèse de doctorat de l'Ecole Centrale Paris (2010)

[9] Paviot, T., Cheutet, V., Lamouri, S.: Design and logistics IT federation through Product Lifecycle Support standard. In: PLM 2009, Bath, UK, July 6-8 (2009)

[10] Guyot, E., Ducellier, G., Eynard, B., Girard, P., Gallet, T.: Product data and digital mock-up exchange based on PLM. In: Proceedings of PLM 2007, Milano, Italy, July 1113 (2007)

[11] Wiederhold, G.: Mediators in the Architecture of Future Information Systems Gio Wiederhold. The IEEE Computer Magazine 25(3), 1-38 (1992)

[12] Booth, D., Haas, H., McCabe, F., Newcomer, E., Champion, M., Ferris, C., Orhcard, D.: Web Services Architecture. W3C Working Group, W3C Working Group Note (2004)

[13] Bénaben, F., Touzi, J., Rajsiri, V., Truptil, S.: Mediation Information System Design in a Collaborative SOA Context through a MDD Approach. In: MDISIS 2008, Montpellier, France, June 16 (2008)

[14] Zimmermann, A., Krötzsch, M., Euzenat, J., Hitzler, P.: Formalizing Ontology Alignment and its Operations with Category Theory. In: Formal Ontology in Information Systems, pp. 277-288 (2006)

[15] Tursi, A., Panetto, H., Morel, G., Dassisti, M.: Ontological approach for products-centric information system interoperability in networked manufacturing enterprises. Annual Reviews in Control 33(2), 238-245 (2009)

[16] Lee, S.-H., Jeong, Y.-S.: A system integration framework through development of ISO 10303-based product model for steel bridges. Automation in Construction 15(2), 212228 (2006)

[17] Rachuri, S., Subrahmanian, E., Bouras, A., Fenves, S.J., Foufou, S., Sriram, R.D.: Information sharing and exchange in the context of product lifecycle management: Role of standards. Computer-Aided Design 40(7), 789-800 (2008) 
[18] Laguionie, R., Rauch, M., Hascoet, J.: Toolpaths programming in an intelligent STEPNC manufacturing context. Journal of Machine Engineering 8(1), 33-43 (2008)

[19] Gallaher, M.P., O'Connor, A., Phelps, T.: Economic Impact Assessment of the International Standard for the Exchange of Product Model Data (STEP) in Transportation Equipment Industries. NIST Report (2002)

[20] Gruber, T.R.: Ontolingua: A Mechanism to Support Portable Ontologies. KSL 9166 581(1), 1-61 (1992)

[21] Benjamins, V.R., Contreras, J., Corcho, O., Gómez-Pérez, A.: Six Challenges for the Semantic Web. Challenges 1(1), 1-15 (2001)

[22] Matthews, B., Brickley, D., Dodds, L.: Semantic Web Technologies. JISC Technology and Standards Watch (2005)

[23] Mellor, S.J., Uhl, A., Weise, D.: Model-Driven Architecture Models and Metamodels. OMG white paper, pp. 290-297 (2000)

[24] Naumenko, A., Wegmann, A.: Two approaches in system modeling and their illustrations with mda and RM-ODP. In: ICEIS, Angers, France, April 23-26 (2003)

[25] Vernadat, F.: Technical, semantic and organizational issues of enterprise interoperability and networking. Annual Reviews in Control 34(1), 139-144 (2010)

[26] EIF.: European Interoperability Framework for pan-European eGovernment Services. In: Interoperable Delivery of European eGovernment Services to Public Administrations (2004)

[27] Chen, D., Doumeingts, G., Vernadat, F.: Architectures for enterprise integration and interoperability: Past, present and future. Computers in Industry 59(7), 647-659 (2008)

[28] Nguyen Van, T.: System engineering for collaborating data management systems: Application to design/simulation loop, $\mathrm{PhD}$ thesis from Ecole Centrale Paris (2006)

[29] Assouroko, I., Ducellier, G., Eynard, B., Boutinaud, P.D.: Semantic-based approach for the integration of product design and numerical simulation. In: PLM 2011, Eindhoven, Netherland, July 11-13 (2011)

[30] Li, C., Mcmahon, C., Newnes, L., Liu, Y.: Ontology-Based Annotation in PLM Systems. In: International Conference on Product Lifecycle Management (2010)

[31] Barbau, R., Krima, S., Rachuri, S., Narayanan, A., Fiorentini, X., Foufou, S., Sriram, R.D.: OntoSTEP: Enriching product model data using ontologies. Computer-Aided Design 44(6), 575-590 (2012)

[32] Catalano, C.E., Camossi, E., Ferrandes, R., Cheutet, V., Sevilmis, N.: A product design ontology for enhancing shape processing in design workflows. Journal of Intelligent Manufacturing 20(5), 553-567 (2008)

[33] Troussier, N.: A Way to Identify and Manage the Knowledge Provided by Mechanical Simulations in Engineering Design. Computing and Information Systems 7(3), 79-84 (2000)

[34] Etienne, A., Guyot, E., Van Wijk, D., Roucoules, L.: Specifications and Development of Interoperability Solution dedicated to Multiple Expertise Collaboration in a Design Framewor. International Journal of Computer Integrated Manufacturing, 1-14 (2011)

[35] Valilai, O., Houshmand, M.: INFELT STEP: An integrated and interoperable platform for collaborative CAD/CAPP/CAM/CNC machining systems based on STEP standard. International Journal of Computer Integrated Manufacturing 23(11), 1097-1117 (2010)

[36] Nassehi, A., Newman, S.T., Xu, X.W., Rosso, R.S.U.: Toward interoperable CNC manufacturing. International Journal of Computer Integrated Manufacturing 21(2), 222$230(2008)$

[37] Jun, H.-B., Kiritsis, D., Xirouchakis, P.: Research issues on closed-loop PLM. Computers in Industry 58(8-9), 855-868 (2007)

[38] Pratt, M.J.: ISO 10303: the STEP Standard for Product data Exchange and its capabilities. International Journal Product Lifecycle Management 1(1), 86-94 (2005) 
[39] Newman, S.T., Nassehi, A., Xu, X.W., Rosso, R.S.U., Wang, L., Yusof, Y., Ali, L., Liu, R., Zheng, L.Y., Kumar, S., Vichare, P., Dhokia, V.: Strategic advantages of interoperability for global manufacturing using $\mathrm{CNC}$ technology. Robotics and Computer-Integrated Manufacturing 24(6), 699-708 (2008)

[40] Biahmou, A., Fröhlich, A., Stjepandic, J.: Improving Interoperability in Mechatronic Product Developement. In: PLM 2010, Bremen, Germany, July 12-14 (2010)

[41] Tan, A.R., Matzen, D., McAloone, T.C., Evans, S.: Strategies for designing and developing services for manufacturing firms. CIRP Journal of Manufacturing Science and Technology 3(2), 90-97 (2010)

[42] Harik, R., Capponi, V., Lombard, M., Ris, G.: Enhanced functions supporting process planning for aircraft structural parts. Computational Engineering in Systems Applications (2006)

[43] Bernard, A., Delplace, J.-C., Perry, N., Gabriel, S.: Integration of CAD and rapid manufacturing for sand casting optimisation. Rapid Prototyping Journal 9(5), 327-333 (2003)

[44] Martin, L., Moraru, G., Véron, P.: Development of an integrated tool for the foundry industry. In: 6th International Conference on Engineering, Design and Manufacturing in Mechanical (IDMME), Grenoble, France, May 17-19 (2006)

[45] Le Duigou, J., Bernard, A., Perry, N.: Framework for Product Lifecycle Management integration in Small and Medium Enterprises networks. Computer-Aided Design 8(1) (2012)

[46] Kuo, T., Huang, S., Zhang, H.: Design for manufacture and design for ' $X$ ': concepts, applications, and perspectives. Computers \& Industrial Engineering 41(3), 241-260 (2001)

[47] Suh, S.-H., Shin, S.-J., Yoon, J.-S., Um, J.-M.: UbiDM: A new paradigm for product design and manufacturing via ubiquitous computing technology. International Journal of Computer Integrated Manufacturing 21(5), 540-549 (2008)

[48] Demoly, F., Toussaint, L., Eynard, B., Kiritsis, D., Gomes, S.: Geometric skeleton computation enabling concurrent product engineering and assembly sequence planning. Computer-Aided Design 43(12), 1654-1673 (2011)

[49] Mantripragada, R.: Assembly oriented design: concepts algorithms and computational tools. Thesis (Ph. D.)- Massachusetts Institute of Technology (1998)

[50] Fenves, S.J., Foufou, S., Bock, C., Sriram, R.D.: CPM: A Core Model for Product Data. Journal of Computing and Information Science in Engineering 8(1), 1-14 (2008)

[51] Chen, D.: Enterprise interoperability framework. In: Proceedings of Entrerpise Modelling and Ontologies for Interoperability, Luxembourg, June 5-6 (2006)

[52] Xu, X.W., Wang, H., Mao, J., Newman, S.T., Kramer, T.R., Proctor, F.M., Michaloski, J.L.: STEP-compliant NC research: the search for intelligent CAD/CAPP/CAM/CNC integration. International Journal of Production Research 43(17), 3703-3743 (2005)

[53] Van Houten, F.: Manufacturing interfaces. CIRP Annals - Manufacturing Technology 41(2), 699-710 (1992)

[54] Paviot, T.: MultiCAD/MultiPDM integration framework. PLM 2008, Seoul, Korea (July 2008)

[55] Elheni-Daldoul, D., Le Duigou, J., Eynard, B., Hajri-Gabouj, S.: Enterprise information systems' interoperability: Focus on PLM challenges. In: Emmanouilidis, C., Taisch, M., Kiritsis, D. (eds.) APMS 2012, Part II. IFIP AICT, vol. 398, pp. 184-191. Springer, Heidelberg (2013) 